\title{
Pneumologia
}

\section{Lung cancer and chronic obstructive pulmonary disease association: epidemiology, diagnostic and treatment aspects}

Camelia Badescu*

Abstract

Department of Bronchology, "Marius Nasta” Institute of Pneumophthisiology, Bucharest, Romania.

\section{English:}

Chronic obstructive pulmonary disease (COPD) and lung cancer (LC) occupy first place among diseases with high incidence and mortality and become a genuine health problem through costs for the medical system. COPD is considered an independent risk factor for LC, in addition to smoking and occupational exposure. Prevention policies and early diagnosis and treatment may contribute to the decrease in the incidence of both diseases. This article reviews the epidemiological overlaps between the two diseases and the particular features of the diagnosis and treatment of LC in COPD patients.

Keywords

\section{Asocierea neoplasmului bronho-pulmonar cu bronhopneumopatia obstructive cronică: aspect epidemiologice, diagnostice și de tratament}

Rezumat

\begin{abstract}
Romanian:
Bronhopneumopatia obstructivă cronică (BPOC) si neoplasmul bronho-pulmonar (NBP) se află pe primele locuri în lume în ceea ce privește incidența și mortalitatea și devin o problemă de sănătate publică raportat la costurile pentru sistemul medical. BPOC este considerat un factor de risc independent pentru NBP, pe lângă fumat si expunerea ocupatională. Politicile de preventie împreună cu diagnosticul și tratamentul instituite precoce pot contribui la scăderea incidenței ambelor afecțiuni. Articolul trece în revistă suprapunerile epidemiologice ale celor două maladii și particularitățile de diagnostic și tratament al NBP la pacienții cu BPOC.
\end{abstract}

Cuvinte-cheie

bronhopneumopatie cronica obstructiva $\bullet$ neoplasm bronho-pulmonar $・$ diagnostic precoce $\bullet$ mortalitate

*Corresponding author: Camelia Badescu

E-mail: cameliagbadescu@yahoo.com 


\section{Epidemiology of chronic obstructive pulmonary} disease and LC

Chronic obstructive pulmonary disease (COPD) is a chronic condition that narrows the inflamed aerial pathways and destroys the alveoli. It is the leading cause of morbidity and mortality worldwide, and it is estimated that it will be the third cause of death until 2030, after ischaemic heart disease and cerebrovascular diseases. Although cigarette smoking ranks first among the causes of COPD, it is estimated that $20 \%$ of people developing COPD are non-smokers (1). Other possible risk factors may be abnormal sensitivity or an exaggerated response to several stimuli such as inhaled substances or other types of exposure-passive smoking, use of solid fuels, exposure to environmental dust, workplace organic materials, or air pollution (2).

The prevalence of COPD is increasing and could now be twice as high if we were to consider that COPD is underdiagnosed and take into account COPD caused by other factors, except cigarette smoke. In developed countries, the prevalence is between 7.8 and $13 \%$ depending on the age of the studied population (3). Exposure to cigarette smoke induces a further increase in the risk of developing COPD when other risk factors are present (4).

In Romania, according to a study conducted between 2007 and 2016, the prevalence of COPD, followed an upward trend, recording an increase of $\sim 50 \%$, with most cases in the western part of the country and fewer in the southeastern part of the country. The incidence of COPD was higher in rural areas in 2016, and males were more frequently affected (5). Smoking continues to be (alongside other risk factors) the leading cause for the presence of COPD in Romania too. Also, in our country, the consumption of electronic cigarettes has led to the increase of COPD cases over the last two years. Long-term epidemiological studies should be conducted to discover the effects of other substances found in these cigarettes as well as the impact that these heated substances have on the lungs and other organs.

Both in COPD and lung cancer (LC), exposure to cigarette smoke and other emissions represents the main risk factor for the onset of the two diseases. Chronic inflammation and oxidative stress, caused by various emissions in the lung tissue, precede the development of dysplasia that can evolve to carcinoma in situ and LC.

Active and passive smoking cessation and discontinuation of exposure to the pollutants is necessary at any time in life to prevent their harmful effect on the respiratory epithelium.

The prevalence of LC is $\sim 2.5$ times higher in patients with moderate or severe COPD compared to patients with mild or no COPD (6).
Incidence and mortality through LC typically show a rapid expansion around the world. The LC incidence varies proportionally with tobacco consumption and air quality in the population. The explanation is elaborate, and it reflects both the age of the population and the continuous ageing process. Regarding LC, some of the changes in prevalence and risk factor distribution are associated with socioeconomic development. LC has the highest incidence in the world in Micronesia/Polynesia $(52.2 \%$ in men and $24.3 \%$ in women), and in Europe where the highest incidence is in Hungary (49.3\% in men and $11.9 \%$ in women). Men all over the world are more affected by LC (7). In the last century, LC has become one of the most common neoplasms for both genders and the most common cause of oncological death around the world. Because of the growing number of new LC cases, from 22 cases published in 1840 , to 374 in 1912 and up to 1.8 million new cases diagnosed in 2012 (8), there is a need for discovering new risk factors and also easy access to education and communication systems.

In the US, in 2018, of all oncological deaths, $26 \%$ were due to LC. LC is the second most common malignant disease in the world after prostate cancer in men and breast cancer in women (9).

In Romania, there is still no National Register for LC. The LC incidence in Romania is included in the incidences of the South Eastern area of Europe and calculated by extrapolation based on the values obtained from the surrounding areas. Globally, there are only a few states that have cancer registers. Only one in four countries reports accurate data regarding incidence and mortality by cancer (10). For the rest of the country, indices are calculated according to neighbouring countries and isolated studies published by health specialists.

The existence of an LC register would bring more benefits. First, the possession of accurate data on LC would lead to the development of prevention strategies, early diagnosis methods, and treatment options that would lead to a decrease in incidence and mortality (benefits for both patient and health system by generating lower costs in supporting these patients).

\section{Diagnosis of LC and COPD}

COPD should be considered as a possible diagnosis in any patient at risk for the disease (smokers, patients with exposure 
to air pollutants, or biomass such as solid fuels), with chronic productive cough and dyspnoea.

Spirometry is the primary investigation performed in these patients; it defines irreversible obstruction in symptomatic patients (Tiffeneau index $<0.7$ ) and assesses the severity of airflow obstruction with prognostic value.

The 'ABCD' evaluation of COPD risk assesses the impact of the disease on patients. It combines the severity of symptoms, the risk of exacerbations, and the patient's comorbidities. According to the GOLD 2019 guidelines, early and correct diagnosis in COPD will ensure appropriate early treatment.

LC may be one of the comorbidities of COPD, and therefore, we must actively seek it in these patients.

Usually, patients with LC present respiratory symptoms, general symptoms, or symptoms that are the expression of other organ damage and may thus indicate the extension of the disease. The most common symptoms are cough, chest pain, dyspnoea, haemoptysis, dysphonia, and weight loss.

A meta-analysis published in 2018 reveals that the symptoms encountered with the highest frequency in studies, with significant value for the diagnosis of LC, are haemoptysis and dyspnoea, followed by cough, chest pain, and weight loss (11). Unfortunately, many patients with LC are still diagnosed in advanced stages of the disease, when palliative treatment remains the only therapeutic option.

The importance of a multidisciplinary team gets more and more recognised in diagnostic centres. All physicians have a role in establishing the diagnosis and providing treatment as quickly as possible. The goal is to improve both the patient's quality of life and their survival. The general practitioner has the first contact with the patient; the pulmonologist initiates investigations, the radiologist assists with diagnosis and staging, the bronchologist and pathologist make staging and histopathologic diagnosis possible, and the surgeon and oncologist contribute to diagnosis and treatment; thus, all practitioners have an essential impact.

The first investigation that raises concern for the diagnosis of LC remains the thoracic chest X-ray. The radiography is less sensitive than computed tomography (CT); it is responsible for false-negative results in $\sim 25 \%$ of cases (12).

Chest CT with intravenous (IV) contrast completed with cerebral, cervical, abdominal, and pelvic examinations for a complete staging represents the essential imaging technique used for the diagnosis of LC. CT will be completed with a positron emission computed tomography (PET-CT) scan for comprehensive staging, especially for $N$ (nodes) and $M$ (metastasis).

Bronchoscopy and biopsy with modern techniques (Autofluorescence - AF, narrow-band imaging - NBI and endobronchial ultrasound EBUS) can offer the possibility of an early diagnostic in LC.
AF uses a blue light source and can highlight dysplastic or minimally invasive lesions. NBI shows the pathologic thickness of the mucosa and indicates which is the best region for performing the biopsy. The sensitivity of these techniques increases when used together. AF and NBI are also used to asses edges after surgical resections (13).

In the case of a suspected pleural tumour, liquid and pleural biopsy have an essential role in establishing the diagnosis and confirming the neoplastic aetiology.

Accurate staging is crucial when choosing the proper treatment. In patients with discrete mediastinal nodules (no matter if they are PET-CT positive or negative), EBUS or mediastinoscopy is essential for staging (14).

Surgical techniques proved to be useful in patients in which less invasive investigations are not an option.

The most common histological types of LC are also the most studied. Adenocarcinoma and squamous carcinoma occupy the first place, followed by large cell carcinoma, which is rarer than the first two. In recent years, biomarker testing and genetic profiling (used to determine immunotherapy sensitivity) have developed (15). In reference centres for LC diagnosis, appropriate resources are available for this kind of analysis. In selected cases, targetted therapy and immunotherapy are recommended.

\section{Association of COPD and LC: Diagnostic difficulties}

The symptoms of the two diseases may be similar, at least in the early stages. A heavy smoker patient (or a patient with exposure to noxious) will delay the medical consult because most of the symptoms are identical with the ones in chronic bronchitis caused by exposure to polluting agents.

The appearance of other symptoms, such as haemoptysis, chest pain, weight loss, or fatigue, increases the chances of presentation. In this situation, conducting a chest X-ray can bring new elements for diagnosis and guide further on the investigation plan. If COPD is the diagnosis, then appropriate bronchodilator treatment (according to the stage of the disease). Periodic revaluation (by clinic exam, spirometry, and chest $\mathrm{X}$-ray) is mandatory.

If the symptomatology worsens or other symptoms appear, early presentation for further investigations is vital for immediate diagnosis and treatment of LC, with increased chances of survival and preservation of the quality of life.

There are situations when CT images are highly suggestive for a tumour, although there is no endobronchial expression. These cases require EBUS or surgical biopsy techniques. When the patient has severe/very severe COPD, and a surgical approach becomes risky, the situation gets at least challenging for the medical team that owns the case. 


\section{Connections between LC and COPD}

LC and COPD are caused or aggravated by smoking and other respiratory hazards. Recent evidence provided by screening studies has shown that patients with COPD are particularly susceptible to LC. A proportion varying between 31 and $69 \%$ of patients with COPD develop LC. Multiple previous studies have determined that the severity of the airflow obstruction in COPD is an independent risk factor for LC.

The moment of a COPD diagnosis and the severity of disease may play a role in the development of LC (16). The presence of chronic bronchitis in early pulmonary carcinogenicity was demonstrated by studies, with a latency period of $\sim 15$ years between the diagnosis of chronic bronchitis and the development of LC (17). In some studies, LC appears to be more common in patients with a recently diagnosed COPD than in those with longstanding obstructive airway disease, and it may be 2-3 times more common in patients with a mild-to-moderate obstruction than in those with more advanced disease (18). More mechanisms would seem to explain the relation between COPD and LC: genetic susceptibility, DNA damage and abnormal repair, chronic inflammation, and a favourable milieu. The obvious argument in favour of a shared genetic predisposition linking COPD and LC is based on several facts. In essence, only a minority of smokers develop any of these diseases, while at the same time, most are spared, and also susceptibility has a hereditary component (19).

On the other hand, $\sim 60 \%$ of patients with LC have COPD (20). That is why when diagnosing LC in a patient, COPD must be ruled out, and inquiring about exposure becomes essential for epidemiological reasons. To non-smokers, chronic inflammation secondary to other exposures or other pulmonary pathologies (e.g., pneumonia, tuberculosis) favours the development of preneoplasic lesions. All patients with LC need special attention because of the oncological and surgical complications that may appear.

\section{Treatment in COPD and LC}

Prevention of further damage is the first step for a newly diagnosed COPD patient. Smoking cessation and the removal of environmental risk factors are useful therapeutic approaches. Prevention helps in slowing lung function degradation; the patient needs to approach a healthy lifestyle and accept bronchodilator treatment. Infection prophylaxis includes annual influenza vaccination, anti-haemophilus, and anti-pneumococcal vaccinations (once in a lifetime). Respiratory rehabilitation and oxygen therapy, as needed, are useful in selected patients.
Bronchodilator treatment offers more control over symptoms, the frequency, and severity of exacerbations. It also improves effort tolerance. There are two major classes of inhaled bronchodilators: $\beta 2$-agonists and anticholinergics., with effect on variable periods. Depending on the stage of the disease (according to GOLD recommendations), therapeutical options vary. In less severe cases, a single bronchodilator can be sufficient, while in more severe ones, a combination of two bronchodilators (from different classes) may be necessary. Availability, price, compliance, tolerance, and adverse effects are also important in choosing the right medication. Corticosteroids can be associated in the advanced stages of the disease, by systemic route for a short period (during exacerbations) or by inhalation, in combination with one or two bronchodilators. Methylxanthines are a class with almost historical value (very rarely used) because of the adverse effects and interactions with other drugs.

The patient with COPD is generally aware of his illness, knows what causes the disease, and is careful about his condition of health. In such cases, avoiding factors that can lead to an exacerbation must be a priority. Some studies prove that offering permanent advice at each visit regarding the use of medical devices and rehabilitation exercises adapted to the stage of the disease improved the patient's perception of the disease and treatment adhesion (21).

The patients with very severe obstruction are highly symptomatic, partly due to COPD but also due to other comorbidities, psychological stress, and social isolation. Studies still show a reduced addressability to palliative therapies in these patients (22).

Interventional therapies in COPD, seldom used due to potential risks, are addressed to patients with a functional reserve at least satisfactory (FEV $1>/=20 \%$ of predicted) and who would have a benefit from the surgical reduction of lung volume. Such patients can present emphysema located in the upper pulmonary territories. In contrast, the reduction of pulmonary volume by bronchoscopic route (valve implant) is especially used in patients waiting for lung transplantation as a last therapeutic option (23).

Surgical treatment in LC is an option in the early stages of the disease (maximum IIIA), after a careful evaluation of the risks that it involves. Decisions are usually made after conferring with a multidisciplinary team, especially when treating borderline cases. From an atypical pulmonary resection to a pneumonectomy, all interventions depend on operability and resectability. A multidisciplinary team formed of a pulmonologist, a pathologist, a thoracic surgeon, a bronchologist, an anaesthesiologist, an oncologist, and a radiotherapist will decide whether surgical treatment is an option (24). 


\section{Therapeutic shades related to combination COPD-LC}

Surgery remains the best therapeutic option in LC. As the LC prevalence is more than two times higher in COPD patients, the combination of the two diseases can be a challenge for both physician and patient, especially when the diseases are diagnosed at advanced stages.

After diagnosing COPD in a patient with newly diagnosed LC, the next step is recommending bronchodilator treatment. In patients who meet the resectability and operability criteria, bronchodilator treatment is necessary for improving the pulmonary function and for assuring a rapid recovery after surgery. If the patient does not meet resectability criteria (above stage IIIB), and surgery is necessary for a histopathological diagnosis, recovering the pulmonary reserve becomes crucial to initiate oncological treatment and increase the quality of life.

Patients with LC and COPD usually have many associated diseases, such as cardiovascular and metabolic comorbidities, especially in advanced stages of COPD. The most common conditions associated with LC, besides COPD, are ischaemic heart disease, heart failure, and renal failure (25). Associated cardiovascular diseases and COPD are independent risk factors for increased chemotherapy toxicity, thus influencing the evolution of the oncological treatment. New oncological treatments, like immunotherapy, are currently being used for LC in advanced stages. In particular, they prove to be safe due to the limited number of adverse reactions (26).

The presence of pleural effusions, no matter the aetiology, aggravates the patient's status. After determining its aetiology, specific treatment is mandatory. The presence of secondary determinations (cerebral and bone metastasis are the most frequent) requires special attention because it associates invalidating symptoms. Palliative radiation therapy prescribed for lowering the tumour's volume and obtaining local decompression brings essential improvements in selected cases.

\section{Survival and prognosis in the association of COPD-LC}

Studies demonstrate that in patients with LC, COPD is an independent risk factor associated with reduced survival rates following resections. The risk is higher in patients with stage II-III GOLD COPD compared to patients with stage I COPD. In these cases, the increased risk of relapse influences longterm survival rates (27).

Patients with LC have a higher mortality risk if the LC is associated with COPD. The differences between the two groups, with and without COPD, decrease as the LC stage increases. The same study demonstrated that although the risk of mortality is high in patients with LC and emphysema, it is lower than in patients with LC and COPD. Inadequate treatment of LC, a decline in pulmonary function, and low quality of life lead to poor prognosis (28); the differences between the patients with LC and COPD and the ones with LC but without COPD were less significant in terms of survival. In patients with COPD and LC, the severity of the LC influences the survival time. A stage III LC reduces the survival time by an average of 10 months while a stage IV LC reduces it with $\sim 60 \%$.

\section{Complications}

Pulmonary resections are considered the most useful interventions in LC, especially in the early stages. Postoperative pulmonary complications are still present in $\sim 25 \%$ of patients. These occur, especially in smokers, patients with COPD, obese, male gender, and those aged over 50 years (29). Pneumonia and atelectasis were the most common complications, with an incidence of $\sim 13 \%$. The most important elements associated with a decrease of foreseeable complications were cessation of smoking, improvement of preoperative physical condition, adequate pain control, control of cardiac affections, and secretion drainage (30).

\section{Disabling complications}

After thoracic LC surgery, the most important complications are the infectious ones. In patients with LC and COPD, there is a high risk of postoperative infectious complications (through the retention of endobronchial secretions and at the drain level).

Either after surgery or after intrapleural installations, the risk of infection is increased. When drainage infections occur, the "Eloesser window" or the "open pleural drainage" are techniques that proved to be useful. By performing these manoeuvers, the pleural cavity remains accessible. When not reversed, the procedure produces disability, and it determines an increase in healthcare costs (31).

The primary complication of mediastino-pulmonary tumours with tracheal and oesophageal invasion is the tracheoesophageal fistula, which can occur before, but especially after radiotherapy. Besides chemo and radiotherapy, auxiliary procedures might be necessary, one of the treatment options being to insert prosthetic material in the trachea and oesophagus. Complication of tracheal prosthesis, such as bleeding, neoformation tissue at the ends of the prosthesis, or prosthesis migration, fuel the vicious circle of complications 
making the patient dependent on repeated endobronchial evaluations and interventions (32).

Another serious complication that can even become lifethreatening is the pulmonary torsion, which can occur after a lobectomy. Without prompt intervention, it becomes a functional pneumonectomy, and in a patient with a limited functional lung reserve (due to COPD association) can become invalidating (33).

Fortunately, severe and invalidating complications are rare, thanks to the multidisciplinary team's preoperative assessments.

\section{Conclusions}

COPD is a significant risk factor in the appearance of LC, independent of cigarette consumption. COPD, cigarette smoke, and other emissions determine chronic inflammation and subsequent preneoplastic or malignant changes in the mucous membrane of the respiratory tract. Patients with COPD need careful monitoring using bronchoscopy combined with modern biopsy techniques, and CT scans to increase the chances of discovering pulmonary lesions with oncological risk. The existence of a national register for patients with LC would bring important data regarding epidemiology and mortality, thereby helping to create sustainable prevention policies.

\section{References}

1. Ntritsos G, Franek J, Belbasis L, Christou MA, Markozannes G, Altman P, et al. Gender-specific estimates of COPD prevalence: a systematic review and meta-analysis. International Journal of Chronic Obstructive Pulmonary Disease. 2018;13: 1507-1514.

2. Murray CJ, Vos T, Lozano R, Naghavi M, Flaxman AD, Michaud C, et al. Disability-adjusted life years (DALYs) for 291 diseases and injuries in 21 regions, 1990-2010: a systematic analysis for the Global Burden of Disease Study 2010. Lancet 2012; 380: 2197-2223.

3. Ramírez-Venegas A, Velázquez-Uncal M, Pérez-Hernández R, Guzmán-Bouilloud NE, Falfán-Valencia R, Mayar-Maya ME, et al. Prevalence of COPD and respiratory symptoms associated with biomass smoke exposure in a suburban area. International Journal of Chronic Obstructive Pulmonary Disease. 2018;13: 1727-1734.

4. Vogelmeier CF, Criner GJ, Martinez FJ, Anzueto A, Anzueto A, Bourbeau J, et al. Global strategy for diagnosis, management, and prevention of COPD, global initiative for chronic obstructive lung disease 2017 report. GOLD executive summary. American Journal of Respiratory and Critical Care Medicine. 2017;195: $557-582$.
5. Cucu MA, Cristea C, Calomfirescu C, Matei E, Ursu C, Radulescu S. National Report of Public Health in Romania. 2018; 125-130.

6. Sandelin M, Mindus S, Thuresson M, Lisspers K, Ställberg B, Johansson $G$, et al. Factors associated with lung cancer in COPD patients. International Journal of Chronic Obstructive Pulmonary Disease. 2018;13: 1833-1839.

7. Bray F, Ferlay J, Soerjomatram I, Siegel RL, Torre LA, Jemal A. Global cancer statistics 2018: GLOBOCAN estimates of incidence and mortality worldwide for 36 cancers in 185 countries. CA: A Cancer Journal for Clinicians. 2018;68: 394-424.

8. Groot PM, Wu CC, Brett WC, Munden RF. The epidemiology of lung cancer. Translational Lung Cancer Research. 2018;7: 220-233.

9. Siegel RL, Miller KD, Jemal A. Cancer statistics, 2018. CA: A Cancer Journal for Clinicians. 2018;68: 7-30.

10. Bray F, Ferlay J, Soerjomataram I, Siegel RL, Torre LA, Jemal A. Global Cancer Statistics 2018: GLOBOCAN estimates of incidence and mortality worldwide for 36 cancers, in 185 countries. 2018. https://doi.org/10.3322/caac21492.

11. Okoli GN, Kostopoulou O, Delaney BC. Is symptom-based diagnosis of lung cancer possible? A systematic review and metaanalysis of symptomatic lung cancer prior to diagnosis for comparison with real-time data from routine general practice, UT MD Anderson Cancer Center, November 21, 2018, PLoS ONE. 2018;13(11): e0207686.

12. Bradley S, Abraham S, Grice A, López PR, Wright J, Farragher T, et al. Sensitivity of chest X-ray for lung cancer: systematic review. British Journal of General Practice. 2018;68(S1): bjgp18X696905.

13. Badescu C, Ulmeanu R. Endoscopic methods of early diagnosis of bronchial-pulmonary neoplasm. Pneumologia Magazine. 2017;4: 203-208.

14. Jantz MA. Lung cancer staging: accuracy is critical. Journal of Thoracic Disease. 2019;11(S9): 1322-1324.

15. Planchard D, Popat S, Kerr K, Novello S, Smit EF, Faivre-Finn C, et al. Metastatic non-small cell lung cancer: ESMO Clinical Practice Guidelines for diagnosis, treatment and follow-up. Annals of Oncology. 2018;29(S4): 192-237.

16. Powell HA, lyen-Omofoman B, Baldwin DR, Hubbard RB, Tata LJ. Chronic obstructive pulmonary disease and risk of lung cancer: the importance of smoking and timing of diagnosis. Journal of Thoracic Oncology. 2013;8: 6-11.

17. Koshiol J, Rotunno M, Consonni D, Pesatori AC, De Matteis S, Goldstein AM, et al. Chronic obstructive pulmonary disease and altered risk of lung cancer in a population-based case-control study. PLoS One. 2009;4(10): e7380.

18. Sanchez-Salcedo P, Berto J, de-Torres JP, Campo A, Alcaide $A B$, Bastarrika $G$, et al. Lung cancer screening: fourteen year experience of the Pamplona early detection program (P-IELCAP). Archivos de Bronconeumología. 2015;51: 169-176.

19. Schwartz AG, Ruckdeschel JC. Familial lung cancer: genetic susceptibility and relationship to chronic obstructive pulmonary 
disease. American Journal of Respiratory and Critical Care Medicine. 2006;173: 16-22.

20. Lin H, Lu Y, Lin L, Meng K, Fan J. Does chronic obstructive pulmonary disease relate to poor prognosis in patients with lung cancer? A meta-analysis. Medicine. 2019;98: 11.

21. Dhand R, Mahler DA, Carlin BW, Hanania NA, Ohar JA, Pinto-Plata $V$, et al. Results of a patient survey regarding copd knowledge, treatment experiences, and practices with inhalation devices. Respiratory Care. 2018;63: 833-839.

22. Bloom Cl, Slaich B, Morales DR, Smeeth L, Stone P, Quint JK. Low uptake of palliative care for COPD patients within primary care in the UK. European Respiratory Journal. 2018;51(2): 1701879.

23. Darwiche K, Aigner C. Clinical management of lung volume reduction in end stage emphysema patients. Journal of Thoracic Disease. 2018;10(S23): 2732-2737.

24. Macri A. Preoperative medical preparation of patients with respiratory conditions. Bucharest: University Publishing House "Carol Davila"; 2017.

25. Rios J, Gosain R, Goulart BH, Huang B, Oechsli MN, McDowell JK, et al. Treatment and outcomes of non-small-cell lung cancer patients with high comorbidity. Cancer Management and Research. 2018;10: 167-175.

26. Lee SJ, Lee J, Park YS, Lee CH, Lee SM, Yim JJ, et al. Impact of chronic obstructive pulmonary disease on the mortality of patients with non-small-cell lung cancer. Journal of Thoracic Oncology. 2014;9: 812-817.
27. Saji H, Miyazawa1 T, Sakai H, Kimura Y, Tsuda M, Wakiyama Y, et al. Survival significance of coexisting chronic obstructive pulmonary disease in patients with early lung cancer after curative surgery. Thorac Cancer. 2018;9: 19-24.

28. Shah S, Blanchette CM, Coyle JC, Kowalkowski M, Arthur ST, Howden R. Survival associated with chronic obstructive pulmonary disease among SEER-Medicare beneficiaries with nonsmall-cell lung cancer. International Journal of Chronic Obstructive Pulmonary Disease. 2019;14: 893-903.

29. Yang R, Wu Y, Yao L, Xu J, Zhang S, Du C, et al. Risk factors of postoperative pulmonary complications after minimally invasive anatomic resection for lung cancer. Therapeutics and Clinical Risk Management. 2019;15: 223-231.

30. Villeneuve PJ. Interventions to avoid pulmonary complications after lung cancer resection. Journal of Thoracic Disease. 2018;10: 3781-3788.

31. Villano AM. Open window thoracostomy as an alternative approach to secondarily infected malignant pleural effusion and failure of intrapleural catheter drainage: a case report. AME Case Reports. 2018;2: 12.

32. Buemi L, Stefanelli S, Bichard P, Luscher M, Becker M. Esophageal pulmonary fistula - a rare complication of radiation therapy: a case report. Journal of Medical Case Reports. 2018;12: 116.

33. Nakada T. Yabe M, Misawa T, Tsukamoto Y, Akiba T, Ohtsuka T. Right upper lobe torsion after right lower lobectomy: a rare and potentially life-threatening complication. Case Reports in Pulmonology. 2018;2018: 4. 